\title{
Geological and economic assessment of resources of oil field of the West-Siberian oil and gas province
}

\author{
A.Kh. Ibatullin \\ Postgraduate student, Saint-Petersburg Mining University, Saint-Petersburg, Russia
}

A.M. Zharkov

Doctor of geological and mineralogical Sciences, Saint-Petersburg Mining University, Saint-Petersburg, Russia

O.E. Kochneva

PhD in Geology and Mineralogy, Associate Professor, Saint-Petersburg Mining University, Saint-

Petersburg, Russia

\begin{abstract}
The presence of a geological structure partially determines the formation of the field. In addition, experts need to analyze other parameters that affect the accumulation of hydrocarbons in prospective traps. In this article a feasibility study of geological exploration of West-Siberian deposit was carried out, within which structural maps were built for 24 layers and the profitability of the proposed project was estimated. This article describes different methods (geological and economic) of identifying prospective oil and gas zones and deciding whether to involve the territory in the geological study project.
\end{abstract}

\section{INTRODUCTION}

The oil field is geographically located in the Yamalo-Nenets Autonomous District of the Tyumen Region. In the northeast corner of the license area, structures are identified that could potentially contain hydrocarbon fields. Based on the calculation of the resource potential and the analysis of geological risks, an appraisal was made of the feasibility of prospecting work, a tree of scenarios was built, and an analysis of VOI (value of information) was executed.

Tasks:

1. Construction of 1D-2D geological model, which will be used to evaluate and analyze information;

2. Answer the question about the need for geological prospecting;

3. Assess the resources of field;

4. Assess the appropriateness of conducting geological prospecting in the north-eastern section.

\section{CHOICE OF RESEARCH FACILITIES}

The first stage of the study is the determination of reservoirs. Of the 31 strata of the Cretaceous age, available on the territory of the field, 24 are selected. They are presented in Table 1. The criterion for the selection of strata is a change in isohypses to lower depths in the northeastern part, which leads to the presence of promising positive dome-shaped structures. The main factor in the study of this area was the location of the tectonic structure of 
Table 1. Reservoirs with promising structures in the north-eastern part of the field.

\begin{tabular}{llll}
\hline & \multicolumn{2}{l}{ Age of collectors } & \\
\cline { 2 - 4 } № & Sukhududinskaya suite & Malohetskaya suite & Pokurskaya suite \\
\hline 1 & BU6-3 & MH1 & PC1-3 \\
2 & BU7 & MH3 & PC12-1 \\
3 & BU8 & MH4 & PC15 \\
4 & BU9 & MH5 & PC19 \\
5 & BU10-1 & MH71 & PC20-1 \\
6 & BU10-2 & MH8-9 & PC20-2 \\
7 & BU11-1 & & PC21-1 \\
8 & BU12-2 & & PC21-2 \\
9 & & & PC22-1 \\
10 & & & PC22-2 \\
\hline
\end{tabular}

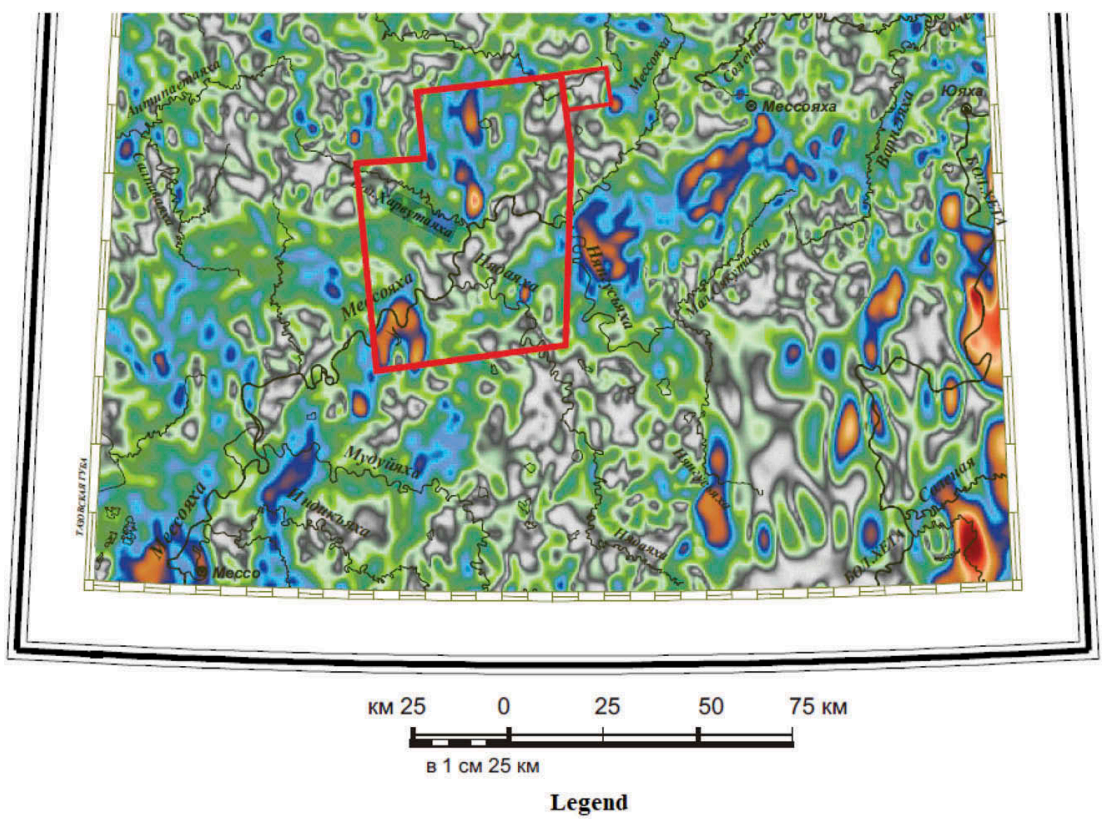

The scale of module full horizontal gradient of gravitional field (E)

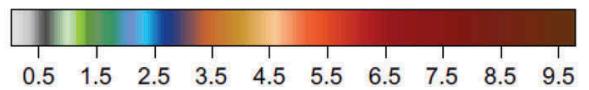

Figure 1. Fragment of map of full horizontal gradient module of gravitational field (Egorov T.N.).

the 3rd order (Figure 2) at the Ust-Port megaswell, adjacent to the Messoyakha megaswell (Egorov et al, 2016). Confirmation of the presence of hydrocarbons at the object of interest is a map of the module of the full horizontal gradient of the gravitational field (Figure 1), which shows abnormally low values in the north-eastern part of the field. When comparing detailed gravitational anomalies constructed from high-precision gravimetric measurements in oil and gas fields, it was found that oil and gas fields are displayed with relatively negative anomalies. 


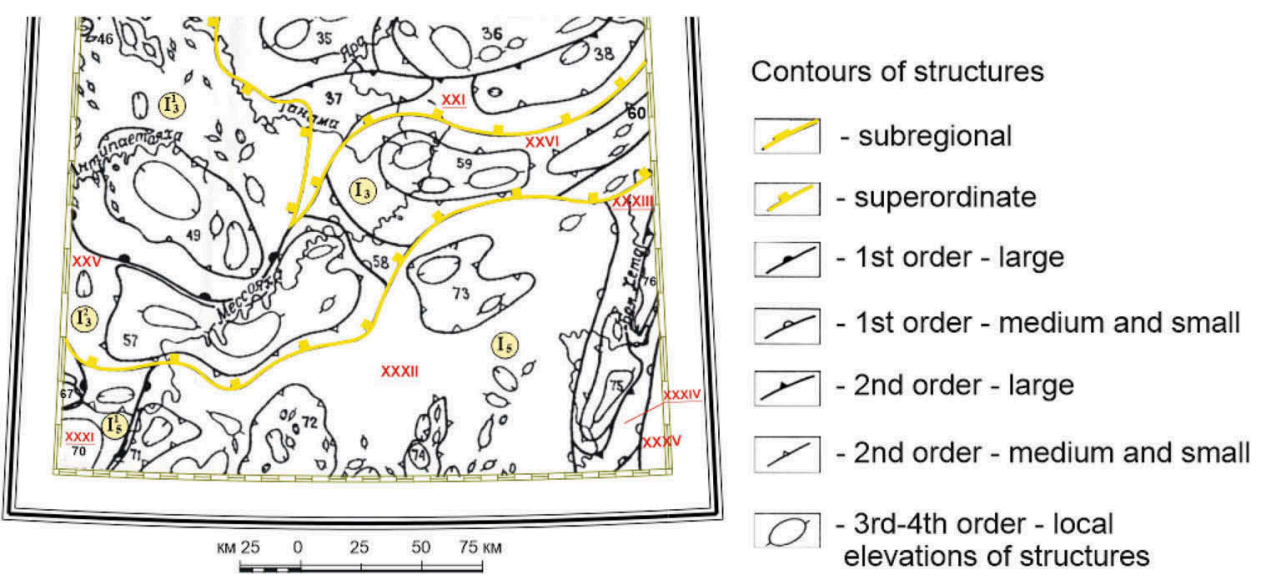

Figure 2. Fragment of tectonic map. $\mathrm{I}_{3}-$ Messoyakh-Antipayutin zone of liner structure; $\mathrm{I}_{3}^{2}-$ Messoyakha Belt magavals.

\section{CALCULATION AND SELECTION GEOLOGICAL PARAMETERS OF OBJECTS}

After selecting the reservoirs of interest, resources were calculated and the geometrical parameters of the fields were specified. As noted earlier, there are no seismic and borehole data outside the licensed area, which significantly complicates further calculations (Prishepa \& Nefedov, 2018; Cherepovitsyn et al, 2018). Using bicubic extrapolation, in Schlumberger Petrel software, structural maps were plotted for all collectors in the area of interest. Bicubic extrapolation is a method of calculating a parameter from two others beyond the area of available data (Gospodarikov \& Zatsepin, 2019). From a geological point of view, this means determining depths from coordinates outside the licensed area. The result was the allocation of 24 traps outside the license area, which are located on the area of $12.5 \mathrm{~km} \times 10 \mathrm{~km}$.

As a result, the geometrical parameters of promising traps were obtained, which are presented in Table 2 with the geological volumes of the traps.

\section{EVALUATION OF INITIAL RECOVERABLE RESOURCES}

Monte-Carlo simulation is a random selection method. The algorithm consists in selecting values from the indicated intervals, substituting them in the necessary formula. The advantage of this method is that it can be used by Microsoft Excel.

Initially, distribution type for each parameter should be specified. Two types of distribution were used in the work:

1. Uniform (GRV, NTG, density, conversion factor, oil recovery factor);

2. Normal (Kporo, Ko).

As a result of work, 8000 realizations were generated for each parameter and 1,344,000 values were obtained at the output. The parameters were taken according to the data of wells drilled at the field earlier (Table 4). The calculation of resources was carried out by the volumetric method according to the formula (1) (Gutman \& Sahakyan, 2017, Nedosekin et al, 2019):

$$
Q=G R V \times N T G \times \text { Kporo } \times K o \times \rho \times \theta \times O R F
$$

where GRV - gross rock volume; NTG - net to gross; Kporo - porosity factor; Ko - oil saturation factor; $\rho$ - density; $\Theta$ - the recalculation factor; ORF - oil recovery factor. Using 
Table 2. Geometric parameters of perspective traps.

\begin{tabular}{lll}
\hline & Gross rock volume & \\
\cline { 2 - 3 } Horizon & Max $\left(\right.$ P10), thous. $\mathrm{m}^{3}$ & Min $(\mathrm{P} 90)$, thous. $\mathrm{m}^{3}$ \\
\hline BU12-2 & 406887.000 & 2202.130 \\
BU11-1 & 398479.000 & 91846.400 \\
BU10-2 & 422400.000 & 18160.800 \\
BU10-1 & 423940.000 & 2643.580 \\
BU9 & 442589.000 & 25475.300 \\
BU8 & 289241.000 & 3510.220 \\
BU7 & 333590.000 & 1329.390 \\
BU6-3 & 392238.000 & 1994.120 \\
MH8-9 & 415825.000 & 18481.500 \\
MH7-1 & 82445.000 & 42239.000 \\
MH5 & 96548.000 & 151.769 \\
MH4 & 119869.000 & 22137.200 \\
MH3 & 168850.000 & 47274.400 \\
MH1 & 288077.000 & 26938.200 \\
PC22-2 & 262542.000 & 88.335 \\
PC22-1 & 305907.000 & 46030.300 \\
PC21-2 & 192563.000 & 4930.790 \\
PC21-1 & 160561.000 & 3417.710 \\
PC20-2 & 118530.000 & 891.833 \\
PC20-1 & 124591.000 & 42.546 \\
PC19 & 91821.800 & 738.545 \\
PC15 & 129476.000 & 4613.470 \\
PC12-1 & 139719.000 & 13031.400 \\
PC1-3 & 930820.000 & 4651.910 \\
\hline & & \\
\hline & & \\
\hline & & \\
MC &
\end{tabular}

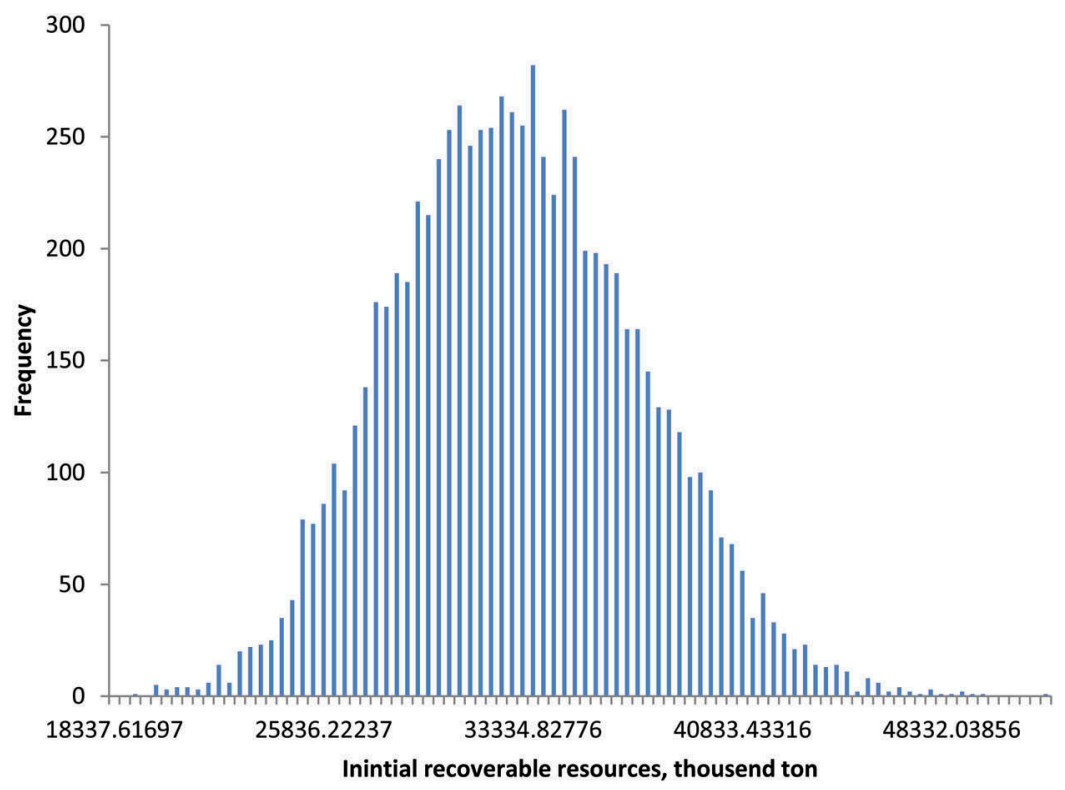

Figure 3. The distribution of resources in the north-eastern part of field No. 1 constructed by Monte-Carlo method. 
Table 3. Initial recoverable resources calculated by the Monte Carlo method.

\begin{tabular}{ll}
\hline Probability & Resources, million tons \\
\hline P90 & 26,97 \\
P50 & 32,42 \\
P10 & 38,29 \\
\hline
\end{tabular}

the Monte-Carlo method, we obtained the normal distribution of resources (Figure 3) calculated in Microsoft Excel and the volumes of initial recoverable resources presented in Table 3.

Additionally, the calculation was performed in the Oracle Crystal Ball software package, which allows to process large amounts of data than the mathematical apparatus of Microsoft Excel al-lows. The methodology for selecting a random distribution is similar to that described above. A feature of the Oracle Crystal Ball software package is that it allows to perform more than 40,000 realization at a time. At the end of the calculation, the distributions of the initial recoverable re-sources were obtained (Figure 4), descriptive statistics (Table 5) and the values of probable re-sources (Table 6).

Analysis of the obtained values of probable resources and descriptive distribution statistics showed similar calculation results, which indicates the reliability of the work performed. The result is also confirmed by the sensitivity value, in which the main contribution to the distribution is made by the values of the geological volume of the rocks $(75.9 \%)$.

\section{DETERMINING THE PROBABILITY OF GEOLOGICAL SUCCESS}

Geological Chance of Success (gCos, probability of geological success) - the probability which the discovery of an oil field will occur, estimated taking into account all existing uncertainties (Glebov, 2016).

This parameter is directly related to conditions for formation of hydrocarbon fields. The main probabilities reflect the result of a particular type of process, which form an accumulation of oil and gas in the reservoir (Shatrov, 2015). Depending on the method, the number of variables can vary from 4 to 6 (Gorbovskaya, 2017). In this work, five parameters were used that reflect the entire process of formation of the field and take into account the necessary conditions for this: Formation of the oil source reservoir (Posr); Migration of hydrocarbons $(\mathrm{Pm})$; The presence of a collector for the accumulation of hydrocarbons (Pc); The presence of traps (Pt); Safety (Ps).

The total probability of occurrence of independent events is equal to their product (2):

$$
g \operatorname{Cos}=\operatorname{Pos} r \times \mathrm{P} m \times \mathrm{P} c \times \mathrm{P} t \times \mathrm{P} s
$$

Probabilities of geological success for each formation are given in Table 7.

\section{BUILDING A DECISION TREE}

The decision tree is a graphical method of information analysis that displays the process of taking managerial decisions in the form of a set of sequential alternative actions and the realization of scenarios characterized by the presence of risks and uncertainties, combinations of which, at given probabilities, lead to the achievement of goals (Figure 5).

After the construction of the Decision Tree, information value (VOI) was estimated including NPV and probability for each outcome (Alekseeva et al, 2019), as well as EMV for all branches separated by probable events (Efimov \& Tashlitskaya, 2013). NPV (Net Present Value): net present value of free cash flow (calculated by formula (3)): 







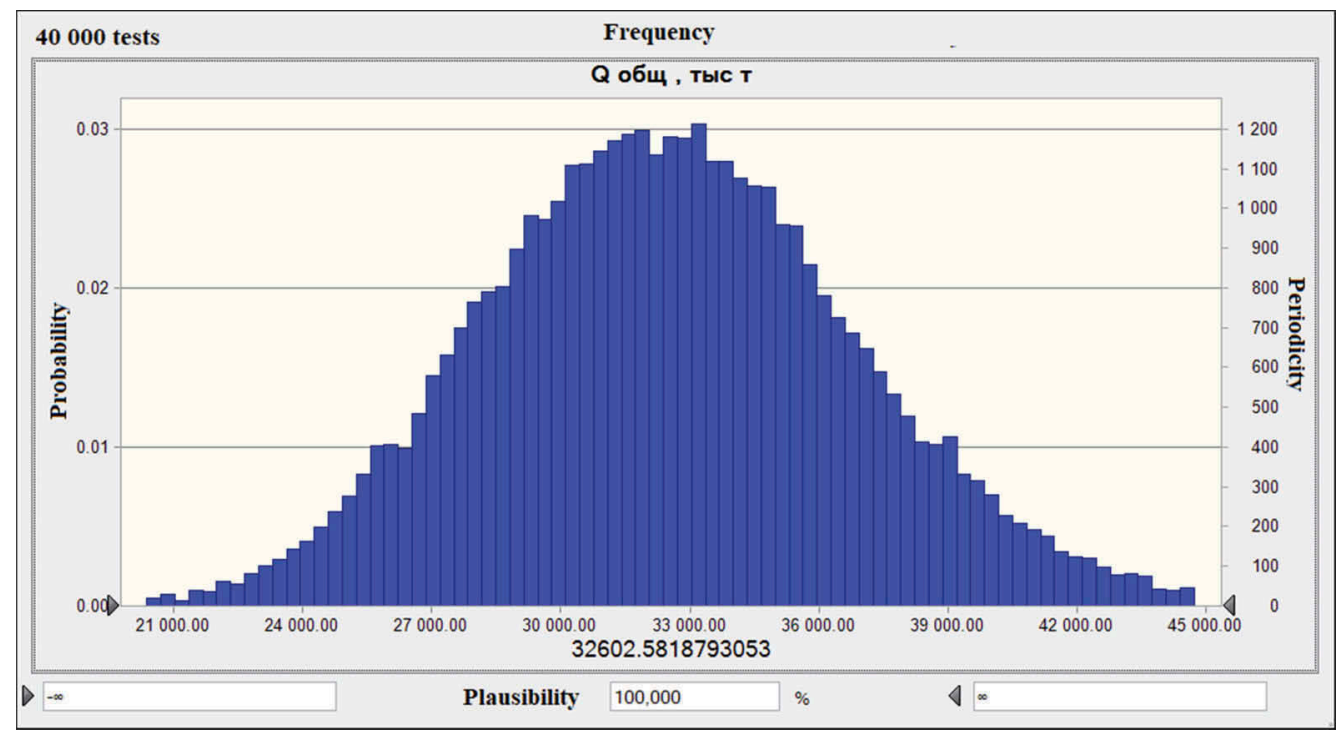

Figure 4. Calculation of the distribution of resources in the north-eastern part of field per-formed in the Oracle Crystal Ball software package.

Table 5. Descriptive statistics of resource allocation.

\begin{tabular}{ll}
\hline Statistics & Forecast values \\
\hline Test & 40000 \\
Base value & 32602,58 \\
Mean & 32550,68 \\
Average & 32439,68 \\
Standard deviation & 4342,53 \\
Discrepancy & 18857562,34 \\
Asymmetry ratio & 0,1797 \\
Excess ratio & 3,03 \\
Coefficient. Variations & 0,1334 \\
Minimum & 16195,62 \\
Maximum & 51952,11 \\
Average square error & 21,71 \\
\hline
\end{tabular}

$$
N P V=\text { Income }_{I}-\text { Consumption }_{I}
$$

EMV (Expected Monetary Value): expected cash value (calculated by formula (4)).

$$
E M V=\sum\left(N P V_{i} \times p_{i}\right)
$$

VOI (Value of Information): The value of Information (DI or VOI) is the increase or decrease in the value of an asset after acquiring information on its further study (Warren, 1983; Reidar, 2009; Whitney, 2010). The Value of Information is calculated by the formula (5):

$$
V O I=E M V_{1}-E M V_{2}
$$


Table 6. Probability resources.

\begin{tabular}{ll}
\hline Percentile & Forecast values, thousand tons \\
\hline P100 & 16195,62 \\
P90 & 27078,05 \\
P80 & 28860,11 \\
P70 & 30190,54 \\
P60 & 31338,40 \\
P50 & 32439,56 \\
P40 & 33521,78 \\
P30 & 34728,50 \\
P20 & 36133,22 \\
P10 & 38207,28 \\
P0 & 51952,11 \\
\hline
\end{tabular}

Table 7. Probability of geological success in studied formations.

\begin{tabular}{lllllll}
\hline Horizon & Oil & Migration & Collector & Trap & Safety & gCos \\
\hline PC1-3 & 1.00 & 1.00 & 0.64 & 0.4 & 0.7 & 0.182 \\
PC12-1 & 1.00 & 1.00 & 0.64 & 0.4 & 0.7 & 0.182 \\
PC15 & 1.00 & 1.00 & 0.65 & 0.4 & 0.68 & 0.178 \\
PC19 & 1.00 & 1.00 & 0.63 & 0.4 & 0.67 & 0.171 \\
PC20-1 & 1.00 & 1.00 & 0.67 & 0.4 & 0.71 & 0.19 \\
PC20-2 & 1.00 & 1.00 & 0.67 & 0.4 & 0.69 & 0.186 \\
PC21-1 & 1.00 & 1.00 & 0.65 & 0.4 & 0.68 & 0.178 \\
PC21-2 & 1.00 & 1.00 & 0.66 & 0.4 & 0.71 & 0.189 \\
PC22-1 & 1.00 & 1.00 & 0.63 & 0.4 & 0.69 & 0.174 \\
PC22-2 & 1.00 & 1.00 & 0.64 & 0.4 & 0.72 & 0.182 \\
MH1 & 1.00 & 1.00 & 0.66 & 0.4 & 0.71 & 0.186 \\
MH3 & 1.00 & 1.00 & 0.64 & 0.4 & 0.71 & 0.181 \\
MH4 & 1.00 & 1.00 & 0.68 & 0.4 & 0.7 & 0.191 \\
MH5 & 1.00 & 1.00 & 0.67 & 0.4 & 0.69 & 0.185 \\
MH7-1 & 1.00 & 1.00 & 0.66 & 0.4 & 0.7 & 0.185 \\
MH8-9 & 1.00 & 1.00 & 0.65 & 0.4 & 0.69 & 0.18 \\
BU6-3 & 1.00 & 1.00 & 0.64 & 0.4 & 0.69 & 0.18 \\
BU7 & 1.00 & 1.00 & 0.66 & 0.4 & 0.69 & 0.184 \\
BU8 & 1.00 & 1.00 & 0.65 & 0.4 & 0.71 & 0.185 \\
BU9 & 1.00 & 1.00 & 0.63 & 0.4 & 0.69 & 0.177 \\
BU10-1 & 1.00 & 1.00 & 0.64 & 0.4 & 0.69 & 0.175 \\
BU10-2 & 1.00 & 1.00 & 0.65 & 0.4 & 0.69 & 0.181 \\
BU11-1 & 1.00 & 1.00 & 0.66 & 0.4 & 0.71 & 0.189 \\
BU12-2 & 1.00 & 1.00 & 0.64 & 0.4 & 0.68 & 0.173 \\
\hline
\end{tabular}

Having analyzed the "Decision Tree", three values of EMV were calculated:

- In the case of the purchase of area (EMV1 $=9.989$ billion rubles)

- In the case of leasing of medical facilities and carrying out of construction and installation works (EMV2 $=9.934$ billion rubles)

- In the case of a leased asset rental without carrying out of construction works (EMV3 = 4.219 billion rubles)

Next, an EMV must be selected, which will be used to evaluate the value of the information. Priorities for further evaluation are EMV2 and EMV3. Since EMV2> EMV1, it is able to provide greater risk reduction.

VOI = EMV2 - EMV3 = 9.934-4 4.219 = 5.714 billion rubles 


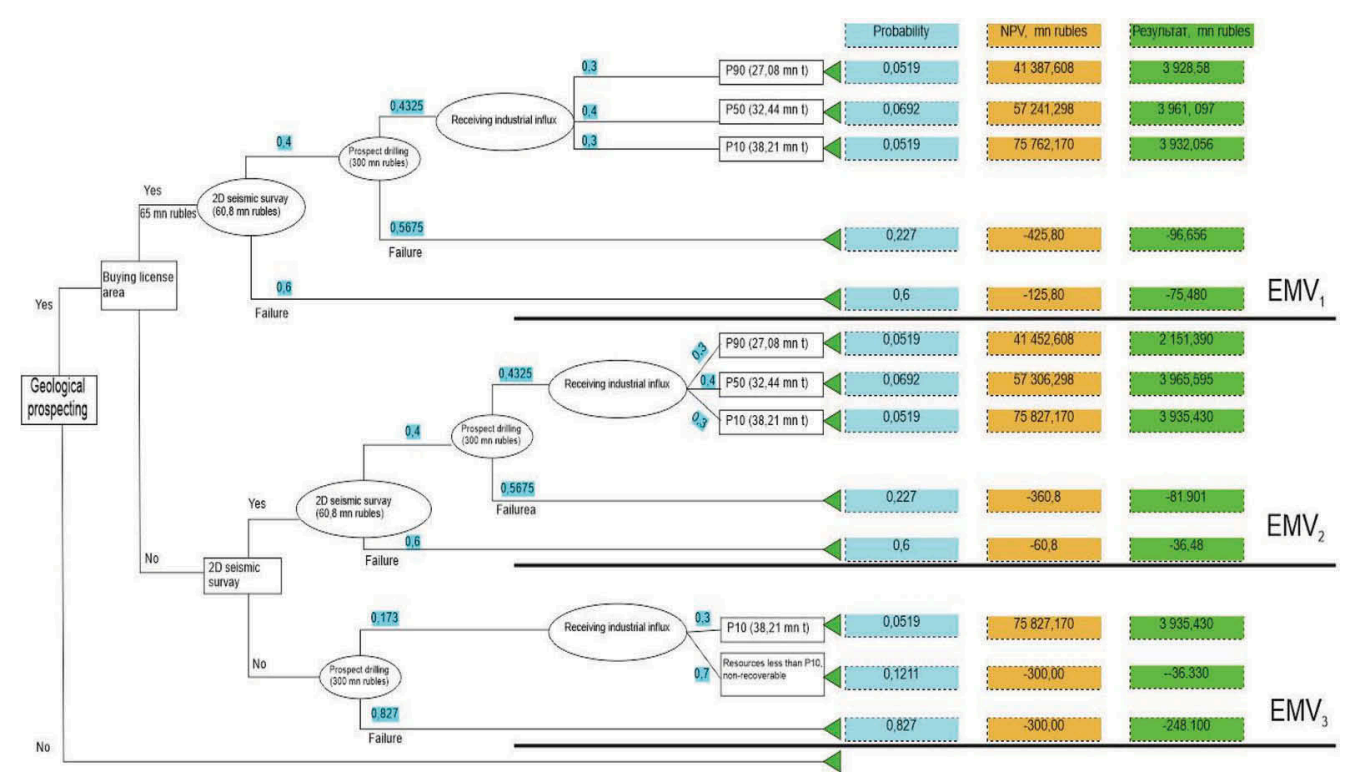

Figure 5. The decision tree.

A positive VOI determines the planning of a solution for $2 \mathrm{D}$ seismic survey and reduces our costs and risks when choosing this scenario by 5.714 billion rubles.

\section{DISCUSSION}

The described methodology for assessing resources allows to study the investigated object from two perspectives: geological and economic. The basis for this analysis is a geological model that defines all the factors and parameters designed to calculate resources and economic indicators. Calculation of the cost of information allows to assess the risks that are always present in the work of specialists. This technique is intended to help the geologist in choosing a priority object for further exploration and to assess risks and uncertainties in the study area. The relevance of the method lies in the fact that the specialist forms a decision on the work, which allows to explore the area with minimal cost and maximum profit.

\section{CONCLUSIONS}

A study of the available data on the area of the field was carried out, a 1D-2D geological model was built, a decision tree was built, an assessment and analysis of the value of information was performed. A feasibility study has been drawn up for geological prospecting. Design solutions for the placement of prospecting work are presented. An assessment of the initial recoverable resources was made, which showed that with a probability of $90 \%$ oil resources will be confirmed in the amount of 26.97 million tons, with a probability of $50 \%$ 32.42 million tons, and a probability of $10 \%$ - 38.29 million tons. Value of Information, amounting to 5.714 billion rubles. The project profitability calculation was estimated at 9.934 billion rubles. An assessment of the value of information, calculated on the basis of the constructed geological model, showed that the geological prospecting with 2D seismic surveys at the area is a reasonable option for choosing a company strategy in order to increase resource potential. 


\section{REFERENCES}

Alekseeva M.B., Bogachev V.F., Gorenburgov M.A. Systemic Diagnostics of the Arctic Industry Development Strategy.Journal of Mining Institute. 2019. Vol.238,p.450-458. DOI 10.31897/PMI.2019.4.450

Cherepovitsyn, A.E., Larichkin, F.D., Vorobiev, A.G., Ibrokhim, A., 2018. Economical prospects of advancement in liquefied natural gas production, Gornyi Zhurnal.

Efimov, A.V. \& Tashlitskaya, A.M. 2013. An example of economic evaluation of projects at the stage of geological prospecting taking into account risks and uncertainties, Oil industry (11): 94-96.

Egorov, A.S., Vinokurov, I.Y., Kalenich, A.P., Belevskaya, E.S., Ageev, A.S. 2016. Deep structure of the Barents-Kara region according to geophysical investigations along 1-AR and 2-AR geotravers, 7th EAGE Saint Petersburg International Conference and Exhibition: Understanding the Harmony of the Earth's Resources Through Integration of Geosciences: 728-732.

Glebov, A.F. 2016. Factor analysis of the geological and technological success and risks of oil and gas seismic survey in modern Russia for 20 years, Seismic survey technologies (4): 5-12.

Gorbovskaya, O.A. 2017. Probability Assessment of Geological Uncertainties: Lessons Learned, SPE Journal.

Gospodarikov, A.P., Zatsepin, M.A., 2019. Mathematical modeling of boundary problems in geomechanics, Gornyi Zhurnal.

Gutman, I.S. \& Sahakyan, M. I. 2017. Methods for calculating reserves and estimating oil and gas resources: textbook, Moscow: Nedra.

Nedosekin A.O., Rejshahrit E.I., Kozlovskij A.N. Strategic Approach to Assessing Economic Sustainability Objects of Mineral Resources Sector of Russia. Journal of Mining Institute. 2019. Vol.237, p.354-360. DOI: 10.31897/PMI.2019.3.354

Prischepa, O., Nefedov, Y., Grokhotov, E. 2019. Geochemical and petrophysical studies of hydrocarbon potential of domanic shale formation (Timan-Pechora petroleum Province), EAGE/SPE Workshop on Shale Science 2019 - Shale Sciences: Theory and Practice. DOI: 10.3997/2214-4609.201900475 ISBN: 978-946282281-8

Prishepa, O.M., Nefedov, Y.V., 2018. Methodical approaches to the allocation of oil and gas accumulation zones on the example of the timan-pechora OGP, Geomodel 2018-20th Conference on Oil and Gas Geological Exploration and Development.

Reidar, B. 2009. Value of Information in the Oil and Gas Industry: Past, Present, and Future, SPE Reservoir Evaluation \& Engineering.

Shatrov, S.V. 2015. Calculation of the probability of discovery of a field taking into account the mutual dependence of the parameters within the estimated formations and structures, Oil and gas geology. Theory and Practice.

Warren, J.E. 1983. The Development Decision: Value of Information, SPE Hydrocarbon Economics and Evaluation Symposium, Dallas, 3-4 March . DOI: 10.2118/11312-MS: SPE.

Whitney, J. T. 2010. On the value of information for spatial problems in the earth sciences. 